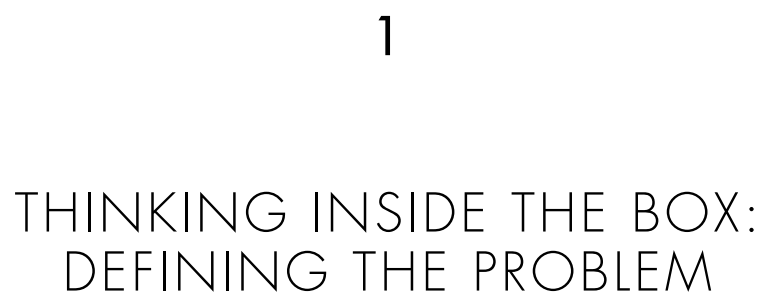

\title{
1.1 OVERVIEW
}

This chapter offers a brief overview of the present state of evidence on regional disparities across Britain. We discuss the importance of different measures of regional economic performance before going on to challenge and extend conventional measures. The post-Brexit environment will pose notable challenges for regional policy, but also offers the opportunity to reassess regional needs and appropriate funding formulae. The chapter is laid out as follows:

- Introduction - Brexit forces us to reconsider regional inequalities and the introduction outlines the key issues that need to be addressed.

- Defining the region - The shifting sands of British regional policy have seen regions successively redefined from the top down. Here the authors reconsider various regional designations. 
- Existing measures - This portion of the chapter outlines the main measures used to assess regional economic performance, most notably gross value added (GVA).

- Commuting - The chapter then describes how commuting has a major distortionary effect on GVA per capita - a measure used by the European Union (EU) in decisions about structural funding.

- Demographics - In this section, we consider the ways in which demographic factors can also have an impact on estimates of regional economic performance and deprivation.

- Towards a better measure - The chapter concludes by putting forward preferred measures of regional economic performance, whilst noting that all can be suffer from some crucial weaknesses that we address throughout the rest of the book.

\subsection{INTRODUCTION}

The Brexit vote has shone a harsh light on something that academics and practitioners have known for years: regional differences matter. In the West Midlands, almost $60 \%$ of votes were to leave the EU. In London, almost $60 \%$ of votes were to remain. Indeed, some have argued that the vote should be seen as the 'revenge of places that don't matter' (RodríguezPose, 2018). This has occurred in spite of the fact that EU structural funding has been concentrated in many of these regions and that a number of them are particularly exposed to EU trade (Los, McCann, Springford, \& Thissen, 2017).

One of the most interesting findings from our recent 'Brexit Roadshow' has been a pervasive sense of inequity and abandonment across a diverse range of communities. 
Comments such as 'they [London] get everything' (De Ruyter, Hearne, Guy, Semmens-Wheeler, \& Goodwin, Forthcoming) and 'nobody cares' alongside disparaging remarks about the local area (De Ruyter et al., Forthcoming) illustrate communities that often seethe with resentment at perceived iniquities in the allocation of services.

Certainly, the extent of spatial inequality within the UK across some measures is striking (McCann, 2016). A man born in Blackpool can expect a lifespan shorter than his Albanian equivalent (Office for National Statistics (ONS), 2016a; World Health Organisation, 2016). A woman born in Kensington, in contrast, can expect to live past her 86th birthday, rivalling Japan for the world's longest life expectancy. These differences are stark - if Blackpool could halve the gap between itself and Barnet in North London then the effects would be transformative. We also note that there is at least prima facie evidence of a link between some of them and the Brexit vote (Bell \& Machin, 2016; Pidd, 2016).

This book makes a fundamental contribution to our understanding of these regional disparities in the light of Brexit, by introducing new measures that can help us further our understanding of those areas that have been 'leftbehind'. In doing so, it is necessary to tackle the fundamental issues in a systematic and logical way. As the infographic below demonstrates, the first is the question is what policy makers and practitioners are ultimately seeking to answer. In order to do this, however, the latter two questions must be addressed. After all, the appropriate policy response is likely to be very different depending on the answer to the second question, and much academic ink has been spilled trying to resolve it. In many ways, however, it is the third question that is most fundamental of all. In order to judge potential policy actions, we need to understand what regional success and failure look like. 
What can and should be done about these disparities in light of Brexit?

Are these disparities due to the places people live... ...or the people who live there?

What do we need to measure to answer this?

Although we know that regional imbalances in the UK span almost every domain, good policy requires more knowledge than this. In particular, it is necessary to quantify 'success' both in terms of living standards and the functional economic geography of an area. Existing measures fail to capture important aspects of both of these and the proposed 'deflated' measures can extend our understanding of these.

This book therefore builds upon official data and international best practice to develop a series of measures with which to assess regional living standards and economic performance before exploring the ramifications of these in light of the UK's vote to leave the EU. We begin by critiquing what has become the de facto measure of regional economic performance - GVA per capita - and draw upon existing research to do so.

The main body of the book is concerned with deriving measures to best capture the true differences in both living standards and productivity across regions, particularly given that both academic evidence (Los et al., 2017) and a majority of experts believe that Brexit threatens to exacerbate these (De Ruyter, Hearne, \& Tsiligiris, in prep.). Regional statistics in the UK do not take into account differences in the cost of living across the country. 
This impacts a wide variety of measures including GVA, household incomes and wages. Happily, methodological developments over recent decades and the emergence of a greater variety of official data sources enable us to make an initial attempt to develop deflators to adjust for these issues. Although some of the methodological distinctions between different deflators are subtle, the overall issue and direction of adjustment is clear.

This is key to developing appropriate policy measures, both to mitigate the impact of Brexit on more vulnerable regions and household and to address many of the insecurities and inequalities that played a factor in the vote to leave the EU. The final portion of the book therefore discusses the policy questions raised by these issues. Brexit affords an opportunity to reassess funding formulae and we argue that this must take the findings of this book into account. Particular attention needs to be paid to the likely evolution of regional policy and funding in the light of Brexit.

\subsection{DEFINING THE REGION}

Recent years have seen a growing awareness of the importance of regional differences within the UK. Indeed, even the Chief Economist of the Bank of England has recently acknowledged the importance of regional differences across the UK economy (Haldane, 2018). It is clear that not only is the UK spatially unbalanced in an economic and social sense, but as continued interest in the so-called 'West Lothian question' shows, there is also a clear political imbalance between the devolved administrations in Scotland, Wales and Northern Ireland and the English regions.

As noted by Benneworth (2006), there are historical antecedents to the present devolution agenda. Added to this is the 
need for a distinction between the region as an economic unit and the region as a facet of identity (Roberts \& Baker, 2006). Indeed, the rise of a more assertive English identity that the Brexit vote has made clear (Henderson et al., 2016) could be seen as threatening this nascent regionalisation of politics. The overwhelming vote against a regional assembly in the North East of England in 2004 (Wood, Valler, Phelps, Raco, \& Shirlow, 2006) might be seen in the same vein. Brexit itself exhibits a significant regional dimension with some recent research finding that regional differences in measured (psychological) character traits might have been important in the referendum (Garretsen, Stoker, Soudis, Martin, \& Rentfrow, 2018).

Nevertheless, in spite of the fact that regional identity in Britain remains somewhat inchoate, the fact remains that the region is often the more sensible level on which to carry out economic policy. In fact, identity in the UK is often local more than regional - witness the fierce rivalry between underland and Newcastle (those who 'mackem' vs. those who 'tackem') or Birmingham and the Black Country. This may, in part, be a result of the historic political centralisation of the UK which has seen regional boundaries adjusted numerous times over the past century without adequate study as to what the functional economic geography looks like (Roberts \& Baker, 2006).

We are left with three potential ways in which to 'regionalise' the UK.

In practical terms, it is not feasible to use TTWAs as they presently stand. Their major attraction is that they potentially capture the economic geography of an area better than any alternative. Unfortunately, for our purposes the $75 \%$ threshold is probably not appropriate, particularly given that mean values can be significantly affected by the commuting patterns of a relatively modest number of high income individuals. Given this, their failure to align with any administrative or political boundary is also a disadvantage. 


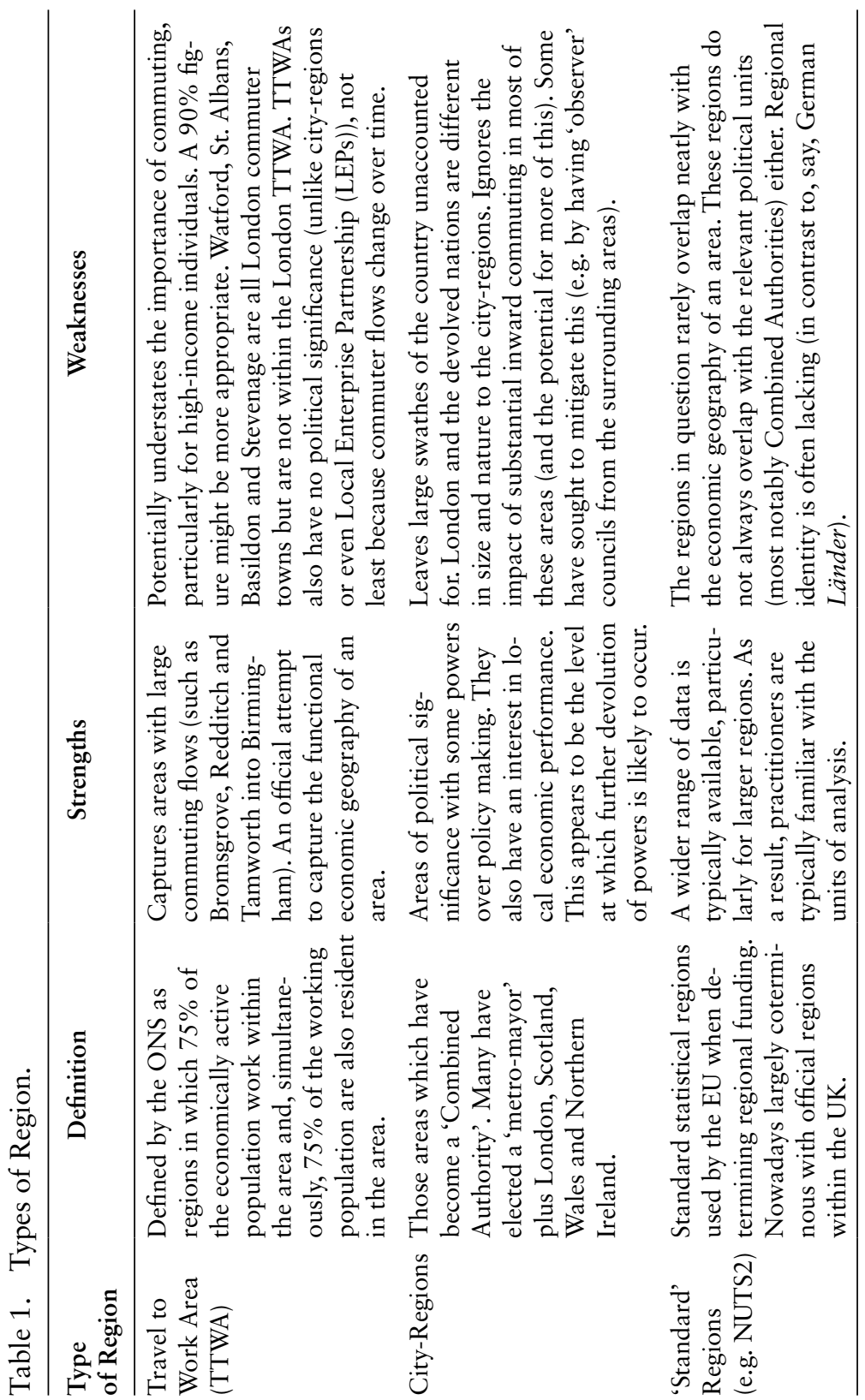


Fundamentally, however, there is a relative paucity of data (particularly price data) on these areas, making them unusable for our purposes.

The attraction of using city-regions lies in their political salience. The emphasis of the so-called 'New Economic Geography' on agglomeration chimes nicely with this political zeitgeist, even though this may be more relevant to present-day developing countries than the UK (Krugman, 2011). Indeed, although the benefits of agglomeration are considered axiomatic by some in the policy community (Swinney, 2016), the empirical evidence is far from incontrovertible.

For example, Frick and Rodriguez-Pose (2018) find that small cities (up to 3 million inhabitants) are most conducive to rapid economic growth and some French data suggest that agglomeration effects are likely to be modest on a plantlevel (Martin, Mayer, \& Mayneris, 2011). Indeed, although some have found that agglomeration might support productivity growth (Rice, Venables, \& Patacchini, 2006), recent work suggests that historical development paths are crucial (Beugelsdijk, Klasing, \& Milionis, 2018).

Research suggests that, in the UK at least, the performance of cities and urban areas is intimately linked to the regions in which they are located (McCann, 2016). In addition, choice of residential location within a region (and the associated differences in cost) may in large part be due to differences in amenities offered. This, together with consumer preferences may partly explain differences between urban centres and their associated peri-urban areas and rural fringes. As a result, we initially consider differences at the level of nomenclature of territorial units for statistics (NUTS) Regions, before reconsidering the impact of our results at a more granular level. In doing so, we find some significant differences from published figures and suggest that this has salience for post-Brexit funding. 


\subsection{EXISTING MEASURES - GDP AND GVA}

Gross domestic product (GDP) per capita (and its sister measure GVA per capita) has come to be widely used by academics and policy makers as a crude proxy for both living standards and economic performance. It has been widely criticised, not least because it ignores environmental degradation and resource use (Dasgupta, 2008). If used as a measure of welfare, GDP is not value free: it assumes that an additional $£ 1$ of income is worth the same whether it accrues to a multi-millionaire or someone who is starving. Nevertheless it remains widely used, in part because it is a well-defined measure and is highly correlated with other measures of wellbeing and progress (e.g. the human development index). Indeed, some have even argued that GDP per capita is a better measure of happiness than most alternatives (Dipietro \& Anoruo, 2006), although this is far from a majority view.

GVA (formerly known as GDP at basic prices), is equal to GDP but excludes taxes and subsidies. In spite of its problems, regional GVA per capita remains used in the policy community. The first part of this book draws upon the work of the ONS (Dunnell, 2009) and Gripaios and Bishop (2006), amongst others, arguing that GVA per capita is not a suitable measure of either regional productivity or regional wellbeing. The second part of the book develops official figures (including both regional GVA and regional gross disposable household income (GDHI) by assessing how subnational variations in purchasing power affect them. It investigates how this alters our perspective on relative regional performance. All of this has direct policy relevance for regional and national policy makers, particularly in light of Brexit.

Areas with GVA per capita of below $90 \%$ of the EU average are eligible for higher levels of funding from the EU's structural funds than those above this threshold (Department 
for Communities and Local Government, 2014). In the UK, this includes a total of 13 regions (including Shropshire \& Staffordshire in the West Midlands). Moreover, the present devolution agenda has meant that a number of local bodies have used GVA per capita as a yardstick against which they should be judged. As such, several LEPs have used it as a key performance metric in recent years (Greater Birmingham and Solihull Local Enterprise Partnership, 2016; Leicester and Leicestershire Local Economic Partnership, 2014).

Similarly, the West Midlands Combined Authority (WMCA) uses GVA in its vision for 2030 - aiming for GVA per head of $5 \%$ above the national average. Indeed, the WMCA strategic economic plan explicitly states, 'increased GVA provides evidence for real growth in the West Midlands' economy' (WMCA, 2016). GVA per capita was quoted in the Government's Industrial Strategy Green Paper as a measure of productivity and thus as justification for the 'essential' process of rebalancing growth across the country (Department for Business Energy \& Industrial Strategy, 2017).

In the academic literature, spatial imbalances in the UK economy are widely commented on (Gardiner, Martin, Sunley, \& Tyler, 2013; Martin, Pike, Tyler, \& Gardiner, 2016; Rice \& Venables, 2003), particularly in the fields of economic geography and regional studies. Even within the academic community, GVA per capita continues to be used as a shorthand for regional economic performance (see e.g. Huggins \& Thompson, 2017; Ivanov \& Webster, 2007; Lee, 2017).

\subsection{COMMUTING AND ITS IMPACT}

Whatever its merits and demerits as a statistic when applied nationwide, GVA per capita is not well suited to regional analysis, particularly for geographically small regions. For 
this reason, the ONS explicitly counsels against using GVA per capita (Dunnell, 2009). To see why, note that it divides the amount produced by those working in an area by the number of people living in an area. For somewhere like the UK with large flows of commuters, this can produce a seriously biased picture.

A clear example of this relates to the comparison of strongly remain-voting Tower Hamlets in London and leave-voting Essex Thames Gateway (home to Basildon, Castle Point and Rochford). The former enjoys a GVA per capita almost 350\% of the national average compared to the latter at just $72 \%$. A superficial examination might, on this basis, suggest a relationship between incomes and the vote for Brexit. However, careful reflection of the data suggests that this might not be the case: residents in Tower Hamlets are only $18 \%$ better off than their counterparts in Essex Thames Gateway, suggesting that this effect is primarily due to commuter flows.

This objection is not new: for over a decade, researchers have noted that commuter flows seriously impact GVA measures, particularly in London (Roberts, 2004). It is this that leads to GVA per capita in Westminster to be almost $800 \%$ above the UK average. In fact, GVA per capita is higher in Islington (represented by the constituencies of Jeremy Corbyn and Emily Thornberry) than in Kensington and Chelsea. Taken to its extreme, GVA per capita in the City of London is $£ 5.2$ million (with a population of circa 8,000 and a workforce of some 483,000). Previously measures of socalled 'residence-based GVA' were produced (ONS, 2017g). This attempted to allocate that portion of GVA attributable to wage earners to their region of residence rather than their region of work. The calculation as it stood led to regional output being apportioned on the basis of neither residency nor workplace but some conceptually unclear hybrid measure of the two. As a result, it is no longer produced by the ONS. 
An obvious corollary of this is that these distortions have a real impact on EU funding flows. GVA per capita in parts of Outer London is far below the national average as a large number of residents commute into Inner London each day. Perversely, therefore, were EU structural funding to be reassessed now, some of the wealthiest parts of Europe (North and East London) would receive higher levels of structural funding than other (much poorer) regions. An attenuated version of this phenomenon is visible in the West Midlands: one of the reasons Shropshire and Staffordshire have such low GVA per capita is due to an outflow of commuters into the metropolitan area (and to a much lesser extent north into Cheshire). The UK's exit from the EU potentially provides an opportunity to reassess some of these funding flows to ensure that they are targeted at the places (and people) that need them most.

\subsection{DEMOGRAPHICS AND THE LABOUR MARKET}

Demographic factors can also have a notable effect on any figures compiled on a per-capita basis. Most obviously, economic output is generated by those in work. The presence of children and the retired in an area will thus increase the denominator without affecting the numerator. This will be true even if they carry out activity that is socially useful, for example, volunteering, that is, not captured by official economic statistics.

Part of the confusion comes about because this is an acceptable practice on a national level. Germany and Japan, for example, struggle with rapidly ageing populations and pensions need to be paid by those still working. This may take the form of the return on assets acquired over a working lifetime or direct transfers but, in either case, effectively entails a transfer from the employed to the retired (Barr, 
2002). Crucially, in the absence of a large net balance of foreign assets, most of this transfer comes within countries.

In contrast, on a regional basis, it is possible (indeed normal) for transfers to take place between regions. The Government may choose to tax workers in London in order to pay the pensions of those living in the South West. Alternatively, the workforce may use part of their income to purchase assets (a house, future pension investments, etc.) from those retirees who are moving to the South West. In either event, this involves a transfer of resources produced in London to be consumed in the South West. This process is both normal and healthy, but it has the effect of flattering the figures for London and depressing those for the South West. As such, whilst it is not true that GVA 'excludes' certain categories of income such as pensions as argued by Gripaios and Bishop (2006), it does measure economic output where it is generated rather than where the income flows to and is thus not a reliable measure of regional welfare.

This effect is quantitatively significant: London has a considerably higher proportion of its population of working age than other parts of the country. Similar effects are visible in other cities. Moreover, this effect has intensified over the past two decades, accounting for a non-trivial portion of the growing disparity between London and the rest of the UK. In 1997, for example, $66.2 \%$ of London's population was of working age, compared to $62 \%$ in the South West. By 2016, these figures had diverged to $67.9 \%$ and $60.9 \%$, respectively. This has a non-trivial impact: it accounts for $17.8 \%$ of the disparity in GVA per head between these two regions (authors' calculations based on ONS, 2017f, 2018a).

Even accounting for these factors, however, important facets of labour market performance have a distinct impact on GVA. Lower employment in an area will, ceteris paribus, depress regional GVA. What's less clear, however, is the extent to which this can be mitigated and whether attempting to do 
so is a desirable policy option. By definition, those who are not employed are not generating measured economic output (although they are almost certainly generating unmeasured economic output - childcare, for example). GVA is affected by both employment and productivity, which may partly explain its popularity. As shown previously, employment can also vary due to demographic factors as well as due to commuting.

Whilst there is almost universal agreement that high unemployment rates are undesirable, GVA per capita is virtually uncorrelated with unemployment, ${ }^{1}$ although there does appear to be some relationship between GVA growth and unemployment rates (see Revoredo-Giha, Leat, \& Renwick, 2012, in relation to Scotland; and Kangasharju, Tavera, and Nijkamp, 2012, for evidence from Finland). Tower Hamlets, for example, enjoyed both the fourth-highest GVA per capita of any local authority and had the joint highest unemployment rate of any local authority. Whilst the boroughs of Inner London are undoubtedly somewhat exceptional in this regard, the more general point stands: on a subregional level, GVA per capita relates poorly to several macroeconomic variables of interest.

More broadly, unemployment today represents just a small fraction of the total number of working-age individuals who are not employed. Part of this is relatively easy to correct for: official statistics view the working age population as being between 16 and 65 even though it is now a legal requirement for those aged between 16 and 18 in England to remain in education or undertake training. Whilst, in theory, it is possible to begin an apprenticeship (or work at least 20 hours per week if one is in part-time education), the scarcity of places means that most continue in full-time education until 18 or 19.

The presence of a large university student population can have a very similar effect on an area as many students choose not to work (or work very few hours). This may be one reason why Oxford, for example, has a GVA per capita below that of Milton Keynes (although both are well above the national 
average). At the other end of the scale, early retirement, whilst not as prominent as it once was, has a very substantial effect on employment amongst those aged over 50. In truth, therefore, these are demographic factors impacting on employment masquerading under the guise of 'economic inactivity'. Whilst they constitute another reason not to use GVA per capita as a measure of economic performance, they also have important consequences for welfare that we shall return to.

All of these issues take on additional salience in light of the vote to leave the EU. In particular, the use of alternative metrics (including those we highlight below) to direct funding flows should be considered. Indeed, it is arguable that use of existing measures has been one of several factors that might have driven some of the imbalances in regional spending identified in Chapter 4. As such, there are notable policy ramifications that the UK should consider, especially in light of the vote to leave the EU, whatever form the UK's future relationship with that body takes.

\subsection{TOWARDS A BETTER MEASURE: GDHI PER CAPITA AND GVA PER WORKER}

GVA per capita is therefore a poor measure of regional economic performance. In light of this, we urge that greater attention be paid to two alternatives: GVA per hour worked and GDHI per capita. The first of these is a measure of productivity and the second measures household incomes (the relevant metric for assessing regional welfare, at least on a monetary basis; a full definition is given in Appendix 1). We believe that this is a better solution than merely reshaping the relevant statistical areas, although the broader argument that statistical areas should take account of the underlying economic geography of an area as argued by Gripaios and Bishop (2006) remains valid. 
Crucially, these two measures maintain the distinction between those who work in an area and those who live in the area. As such, GVA per hour worked measures the amount produced by each member of the workforce per hour in a given region. In practical terms, it gives similar results to GVA per worker but accounts for the fact that hours worked vary across regions (Londoners in particular work slightly longer hours than those living elsewhere). Nevertheless, total hours worked can be difficult to measure accurately, particularly in cases where unpaid overtime is common. As a result, regional GVA per hour worked (which is reported by the ONS) can be somewhat erratic: smoothing the series (e.g. by taking a moving average) is likely to ameliorate this somewhat.

The effect of this is dramatic: pushed up by net-inflows of commuters, a long-hours culture and a high working age population, London's GVA per capita is $76.5 \%$ higher than the national average. Its labour productivity, as measured by its GVA per hour worked (ONS, 2018e), however, is only $33.3 \%$ above the national average. The same is true in reverse for other regions: Yorkshire moves from being $21.5 \%$ below the UK average to $15.2 \%$ below. It is therefore positive that a number of LEPs are now using GVA per worker or GVA per hour as a more effective measure of economic performance (Greater Birmingham and Solihull Local Enterprise Partnership, 2018; North East Local Enterprise Partnership, 2018).

Fig. 1 gives a sense of the magnitude of the distortion. Whilst GVA per capita fails to measure either productivity or living standards, GVA per hour is a measure of the former whilst GDHI per capita is a measure of the latter. Although London stands out as a region where such distortions are particularly prevalent, very noticeable differences between GVA per capita and the other measures also appear in Wales and the North East of England. 


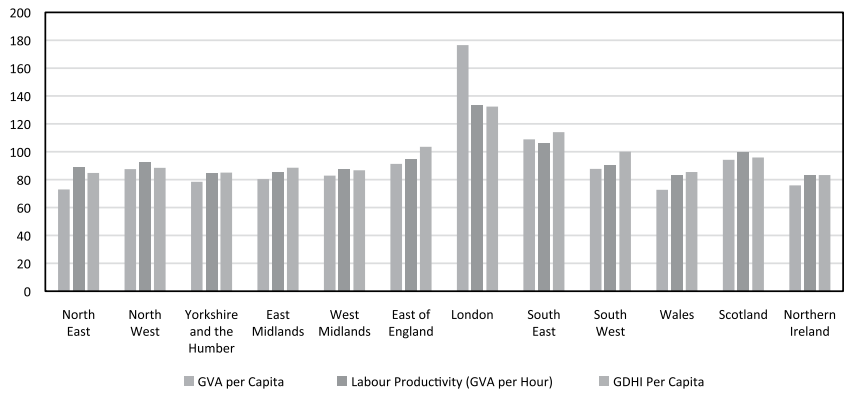

Fig. 1. Comparative Economic Performance.

Source: ONS (2017f, 2018e, 2018f).

The fact that these figures do not take into account differences in prices across regions, together with the difficulty of measuring the size of the financial services and real estate sectors mean that official figures can reasonably be assumed to be an upper bound on regional productivity disparities. The fundamental methodological issue at play here (the absence of subnational price parities) is not unique to the UK - indeed there is an emerging literature on the subject. As such, over the past 20 years a variety of attempts have been made in a number of countries to calculate regional price levels. Due to data limitations these have often been partial but a nascent research agenda is, in fact, developing on the subject.

As in a number of areas regarding economic and social statistics, the United States is in the vanguard of these developments with an official price index and attempts to deflate regional earnings (Aten, Figueroa, Mbu, \& Vengelen, 2017). The Australian Bureau of Statistics produced an experimental set of spatial price indices (Waschka, Milne, Khoo, Quirey, $\&$ Zhao, 2003) although like the work of the ONS, these excluded housing costs (ONS, 2011, 2018g). The methodological approach of the Australian work was broadly similar to that of the ONS' later works (although not earlier attempts 
to compare regional prices (Ball \& Fenwick, 2004; Wingfield, Fenwick, \& Smith, 2005) and our own, with the exception of excluding housing costs.

There have been several pieces of work considering regional price differences within China (Gong \& Meng, 2008; Jiang \& Li, 2006; Li \& Gibson, 2014), although some more recent work has suggested that the 'Law of One Price' holds for some regions (Liu, Su, Chang, \& Xiong, 2018). Within Europe work has been somewhat more limited, although there have been a number of promising studies with regard to Czechia (see e.g. Cadil, Mazouch, Musil, \& Kramulova, 2014), whilst Roos (2006) used an econometric model to estimate regional prices in Germany, showing that East-West differentials are reduced when price differences are accounted for. In Italy, there is now official interest in calculating subnational purchasing power parities (Biggeri, Laureti, \& Polidoro, 2017).

The following chapters are devoted to a discussion of these issues in the UK case and, critically, how new estimates can be used to better understand regional disparities. These regional disparities are the context within which the vote to leave the EU occurred. The Brexit vote did not cause these fissures, but it has exposed them and, if inappropriate policies are pursued, threatens to exaggerate them (Los et al., 2017). As such, a fuller understanding is needed of those regions that have been 'left behind' and this book is a contribution to that wider debate.

\section{NOTE}

1. At NUTS2 level, the correlation between Jan. and Dec. unemployment rate, as measured by the Annual Population Survey (ONS, 2017a) and GVA per capita, as measured by the Regional Accounts (ONS, 2017f) was -0.01 in 2016. 